\title{
Fast Coprecipitation of Calcium Phosphate Nanoparticles inside Gelatin Nanofibers by Tricoaxial Electrospinning
}

\author{
Silvia Panzavolta, ${ }^{1}$ Chiara Gualandi, ${ }^{1}$ Andrea Fiorani, ${ }^{1}$ Barbara Bracci, ${ }^{1}$ \\ Maria Letizia Focarete, ${ }^{1,2}$ and Adriana Bigi ${ }^{1}$ \\ ${ }^{1}$ Department of Chemistry “G. Ciamician” and National Consortium of Materials Science and Technology (INSTM, Bologna RU), \\ University of Bologna, Via Selmi 2, 40126 Bologna, Italy \\ ${ }^{2}$ Health Sciences and Technologies-Interdepartmental Center for Industrial Research (HST-ICIR), University of Bologna, \\ Via Tolara di Sopra 50, Ozzano dell'Emilia, 40064 Bologna, Italy
}

Correspondence should be addressed to Maria Letizia Focarete; marialetizia.focarete@unibo.it

Received 2 February 2016; Revised 4 October 2016; Accepted 5 October 2016

Academic Editor: Christian Brosseau

Copyright (C) 2016 Silvia Panzavolta et al. This is an open access article distributed under the Creative Commons Attribution License, which permits unrestricted use, distribution, and reproduction in any medium, provided the original work is properly cited.

\begin{abstract}
We present an effective method for fabricating electrospun gelatin nanofibers containing well-dispersed inorganic nanoparticles. The new method encompasses the use of a special triaxial needle where mixing calcium and phosphate aqueous solutions in an intermediate needle yield calcium phosphate $(\mathrm{CaP})$ nanoparticles that immediately after precipitation are dragged by the outer polymeric solution and incorporated directly in the electrospinning jet, before nanofiber formation. Gelatin electrospun mats containing different amounts of CaP nanoparticles were prepared and characterized by SEM, TEM, TGA, and stress-strain measurements. The results demonstrate that $\mathrm{CaP}$ particles having diameter of few tens of nanometers were successfully introduced in the gelatin nanofibers during the electrospinning process and that they were well dispersed throughout the fiber length. In addition, the use of the special triaxial needle enabled modulating the $\mathrm{CaP}$ amount in the nanofibers.
\end{abstract}

\section{Introduction}

In recent years electrospinning technology has attracted increasing interest for applications in the field of bone regeneration [1-3]. This scaffold fabrication technique is cheap and scalable; moreover it offers the possibility to process a great variety of polymers, both synthetic and natural, into continuous fibers having micro- to nanometric diameters with controlled surface texture and orientation. The extracellular matrix of bone is a complex nanocomposite with a multilevel hierarchical structure of its two main components, inorganic hydroxyapatite and collagen fibers [4]. Thus, it is not surprising that most of the scaffolds proposed for bone tissue engineering are biodegradable and bioactive polymer/inorganic composites [5-8]. These systems not only mimic bone extracellular matrix but also combine advantages of both polymers and inorganic materials, thus offering a promising approach to overcome the drawbacks encountered when single-component scaffolds are used [9]. Since the polymeric organic phase is poorly bioactive and is scarcely useful for inducing bone regeneration [5], bioactive inorganic substances, such as bioglasses and calcium phosphates, are introduced in polymer matrices in order to confer bioactivity to the scaffolds.

Nonwoven electrospun composite scaffolds for bone tissue engineering are commonly produced by applying two main approaches: (i) direct electrospinning of a dispersion of inorganic particles in a polymeric solution [10] and/or (ii) immersion of the as-spun polymeric scaffolds into calcifying solutions that slowly generate an inorganic coating on the fiber surface (post-mineralization process) [11-14]. In the first approach previously synthesized inorganic particles are added to the polymeric solution to get a homogeneous dispersion, often by using sonication [15-17]. However, this method is not always feasible. To improve the quality and the stability of the suspension some authors increased the hydrophilicity of the polymeric component [18] while others functionalized the inorganic particles at the surface to 


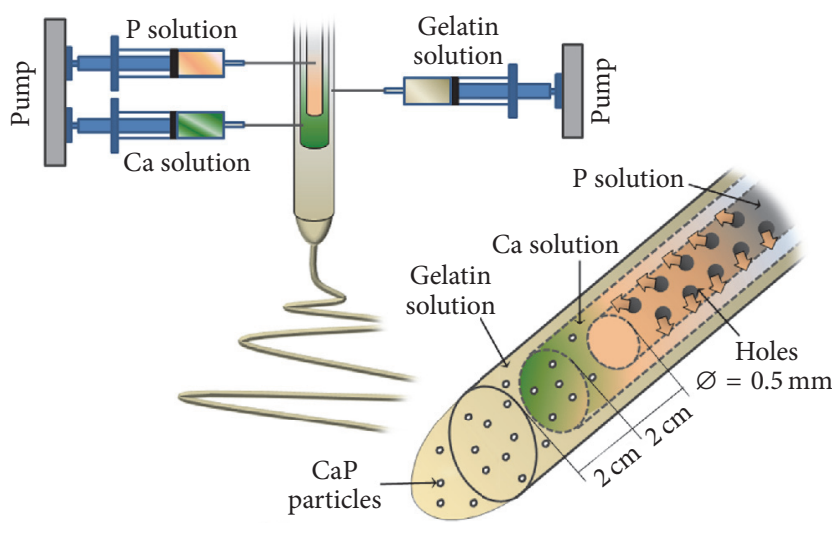

FIGURE 1: Sketch of the triaxial needle configuration and enlargement of the needle internal structure. The feeding solutions were (i) phosphorous-based water solution in the inner needle; (ii) calciumbased water solution in the intermediate needle; (iii) gelatine solution in the outer needle.

enhance the compatibility with the polymeric solution [19]. The requirement to maintain the stability of the suspension over the entire duration of the electrospinning process, to guarantee a constant composition and equal dispersion of the inorganic particles in the polymeric fibers throughout the entire mat thickness, is however not easily fulfilled. To gain a more stable suspension another approach was to precipitate the inorganic particles in the presence of the polymeric phase and then dissolve the composite for electrospinning [20-23].

On the other hand, the post-mineralization approach requires a post-processing step to introduce the inorganic phase in the electrospun scaffold that complicates and prolongs the scaffold fabrication procedure. In addition, the deposition of the inorganic phase on fiber surface may not be homogeneous throughout the entire scaffold thickness.

In this work we developed an alternative approach to fabricate composite electrospun mats that enables the homogeneous dispersion of the inorganic phase in the polymeric fibers thanks to an in situ generation of calcium phosphate $(\mathrm{CaP})$ nanoparticles directly in the electrospinning jet, before nanofiber formation. This was achieved by means of a specifically designed triaxial needle (Figure 1) for the electrospinning process. This particular needle is composed of an inner capillary filled with an aqueous solution containing phosphate ions, an intermediate capillary that brings calcium ions aqueous solution, and an outer needle carrying a polymeric gelatin solution. Gelatin was chosen because it resembles the chemical composition of natural bone ECM, it is highly biocompatible and lowly immunogenic, and furthermore it displays a favorable cellular interaction [14]. The conformation of the inner needle enables extruding the phosphate solution from several holes promoting the mixing with the calcium solution. The three capillaries are mutually positioned, as showed in Figure 1, so that at first the solutions containing calcium (inner needle) and phosphate (intermediate needle) ions come in contact and produce $\mathrm{CaP}$ nanoparticles inside the intermediate needle, before coming in contact with the gelatin solution (ejected in the outer needle). Composite electrospun mats of gelatin containing $\mathrm{CaP}$ nanoparticles have been produced in this work by using the above described approach. The presence and the distribution of the inorganic particles were investigated by Scanning Electron Microscopy equipped with energy dispersed Xray spectrometer, Transmission Electron Microscopy, and Thermogravimetric Analysis. The effect of the presence of the inorganic phase on scaffold mechanical properties has been also investigated by tensile stress-strain measurements.

\section{Materials and Methods}

2.1. Materials. Type A Gelatin (280 Bloom, Italgelatine SpA) from pig skin was used. Acetic acid $(\mathrm{AcOH})$ was purchased from Sigma-Aldrich and used without further purification. Calcium chloride dihydrate $\left(\mathrm{CaCl}_{2} \cdot 2 \mathrm{H}_{2} \mathrm{O}\right)$ and sodium phosphate monobasic dodecahydrate $\left(\mathrm{Na}_{3} \mathrm{PO}_{4} \cdot 12 \mathrm{H}_{2} \mathrm{O}\right)$ were purchased from Carlo Erba and used without further purification.

2.2. Preparation of Electrospun Scaffolds. The in-house built electrospinning apparatus is composed of a high voltage power supply (Spellman SL $50 \mathrm{P}$ 10/CE/230), two syringe pumps (KD Scientific 200 series), a glass syringe, a stainless steel triaxial needle connected to the power supply electrode, and a grounded aluminum collector $(10 \mathrm{~cm} \times 10 \mathrm{~cm})$. The triaxial needle used in the present work (Figure 1) is constituted by an inner needle ( $\mathrm{OD}=0.9 \mathrm{~mm} ; \mathrm{ID}=0.6 \mathrm{~mm})$, positioned concentrically to the intermediate needle $(\mathrm{OD}=1.5 \mathrm{~mm}$; ID $=1.2 \mathrm{~mm})$, and an outer needle $(\mathrm{OD}=2.2 \mathrm{~mm}$; ID $=1.8 \mathrm{~mm})$. The tip of the outer needle protrudes $2 \mathrm{~cm}$ below that of the intermediate one which in turn protrudes $2 \mathrm{~cm}$ below the tip of the inner needle. In addition, the tip of the inner needle presents twenty little holes regularly distributed along the wall for a length of $1 \mathrm{~cm}$. The solutions were dispensed at a controlled flow rate (as specified below) by using the syringe pumps through a Teflon tube to the needles.

Gelatin was dissolved in $\mathrm{AcOH}: \mathrm{H}_{2} \mathrm{O}(60: 40 \mathrm{v} / \mathrm{v})$ at a concentration of $30 \% \mathrm{w} / \mathrm{v}$ to prepare the shell solution. The inner needle was fed by a solution containing different amount of $\mathrm{CaCl}_{2} \cdot 2 \mathrm{H}_{2} \mathrm{O}$, in Double Distilled Water (DDW) (Ca solution), while the intermediate needle contained a solution obtained by dissolving $\mathrm{Na}_{3} \mathrm{PO}_{4} \cdot 12 \mathrm{H}_{2} \mathrm{O}$ in DDW ( $\mathrm{P}$ solution): different concentrations were tested (by keeping $\mathrm{Ca} / \mathrm{P}$ molar ratio equal to 1 ) in order to obtain scaffolds with different inorganic phase contents. The scaffolds were labeled GCaP50, GCaP250, and GCaP375, accordingly to the concentrations of $\mathrm{Ca}$ and $\mathrm{P}$ solutions, that is, 50,250 , and $375 \mathrm{mM}$, respectively. The flow rate of the shell solution was set at $0.3 \mathrm{~mL} / \mathrm{h}$ while those of the inner and intermediate solutions were $0.12 \mathrm{~mL} / \mathrm{h}$. The triaxial needle was placed vertical to the collecting plate at a distance of $20 \mathrm{~cm}$ and the applied voltage was set at $18 \mathrm{kV}$. Mats of pure gelatin $(\mathrm{G})$, used as reference sample, were produced by feeding the inner and intermediate needle with MilliQ water and by using the same electrospinning parameters. Electrospun mats were kept under vacuum over $\mathrm{P}_{2} \mathrm{O}_{5}$ at room temperature (RT) overnight in order to remove residual solvents. 
2.3. Instrumental Techniques. The inorganic phase obtained by electrospraying $\mathrm{Ca}$ and $\mathrm{P}$ solutions was collected on a Titanium disc and characterized by means of X-ray diffraction (XRD). XRD measurements were performed using a PANalytical X'Celerator powder diffractometer. $\mathrm{CuK} \alpha$ radiation was used $(40 \mathrm{~mA}, 40 \mathrm{kV})$. The $2 \theta$ range was from $20^{\circ}$ to $40^{\circ}$ with a step size of $0.05^{\circ}$ and time/step of $20 \mathrm{~s}$. Morphological observations were carried out using a Philips XL-20 Scanning Electron Microscope (SEM) equipped with energy dispersed $\mathrm{X}$-ray spectrometer (EDS) by applying an accelerating voltage of $15 \mathrm{kV}$. Samples were sputter-coated with gold prior SEM analysis. Fiber diameter distributions were determined by using image analysis software (EDAX Genesis) through the measurement of about 150 fibers. Thermogravimetric analysis (TGA) was performed with a TA Instruments TGA2950 thermogravimetric analyzer from RT to $800^{\circ} \mathrm{C}$ (heating rate $10^{\circ} \mathrm{C} \mathrm{min}^{-1}$, purge gas air). Electrospun fibers supported on conventional copper microgrids were observed by using a Philips CM 100 Transmission Electron Microscope (TEM) operating at $80 \mathrm{kV}$. Tensile stress-strain measurements were performed by using a Dynamic Mechanical Thermal Analyzer (DMTA, TA Instruments Q800 series) equipped with tension-film clamps. All the analyses were performed on rectangular strips cut from electrospun mats (width $=5 \mathrm{~mm}$; gauge length about $10 \mathrm{~mm}$; thickness $=0.040 \div 0.090 \mathrm{~mm}$, measured by a microcaliper) by applying a preload force of $0.008 \mathrm{~N}$ and using a cross-head speed of $0.5 \mathrm{~mm} / \mathrm{min}$. Eight replicate specimens were run for each sample and mechanical data, tensile elastic modulus $(E)$, stress at break $\left(\sigma_{b}\right)$, and deformation at break $\left(\varepsilon_{b}\right)$, were given as the average value \pm standard deviation.

\section{Results and Discussion}

The use of supersaturated calcifying solutions to obtain precipitation of poorly crystalline calcium phosphate phases with different stoichiometry is well known in literature [2426]. The $\mathrm{Ca}$ and $\mathrm{P}$ solutions employed in this work have a simplified composition with respect to those previously published [27] which are used to cover metallic substrates with an apatitic coating. In fact, in this study, in order to obtain a fast precipitation of nanoparticles inside the electrospinning needles, the previously used buffered solution containing carbonate ions [28] was substituted with a simple aqueous solution. The triaxial needle with the peculiar configuration shown in Figure 1 was specifically designed to produce calcium phosphate nanoparticles inside the gelatin nanofibers. In brief, the inner capillary is loaded with the $\mathrm{P}$ solution that comes in contact with the Ca solution flowing in the intermediate capillary. The two solutions have the same molar concentrations of calcium and phosphate ions and they are delivered at the same flow rate. Moreover, the appositely perforated inner needle enables mixing of $\mathrm{Ca}$ and $\mathrm{P}$ solutions inside the intermediate capillary to give the precipitation of a calcium phosphate phase. Nanoparticles of $\mathrm{CaP}$, which are expected to precipitate, can be dragged out by the gelatin solution and incorporated inside the polymeric nanofibers. The solutions mixing time can be controlled by regulating the protrusion of the internal needle with respect to the external one.

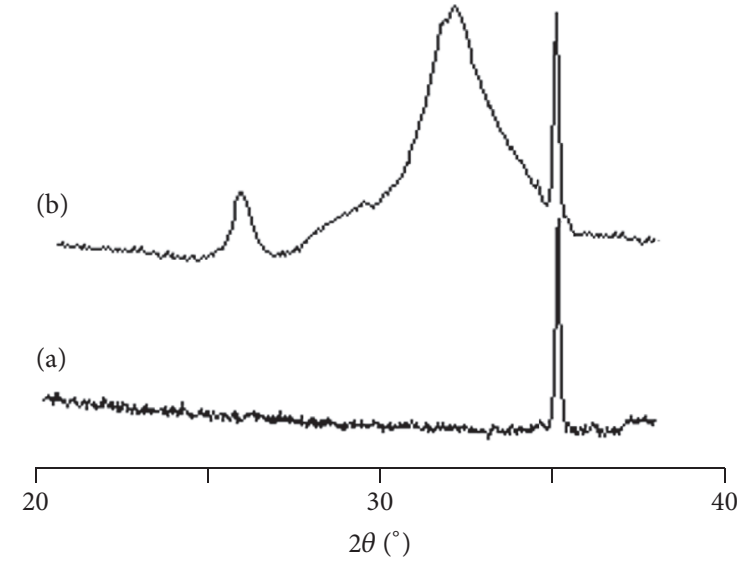

Figure 2: Powder X-ray diffraction patterns of (a) Ti collector; (b) inorganic phase deposited on the Ti collector.

In order to investigate the composition of the inorganic phase, we electrosprayed the $\mathrm{Ca}$ and $\mathrm{P}$ solutions, in absence of gelatin, on a Titanium (Ti) disk collector. The CaP coated disk was accurately rinsed with distilled water before submitting it to XRD analysis, to remove soluble salts (i.e., $\mathrm{NaCl}$ ) formed in the precipitation reaction. The XRD pattern reported in Figure 2(b) shows the presence of a broad peak at about $25,9^{\circ}$ of $2 \theta$ and a more intense and broader peak centered at about $32^{\circ}$ of $2 \theta$, confirming the effective formation of a poorly crystalline apatitic phase. The concentrations of the $\mathrm{Ca}$ and $\mathrm{P}$ solutions were such to yield a $\mathrm{Ca} / \mathrm{P}$ molar ratio of 1.0 . The precipitation of an apatitic phase is in agreement with the $\mathrm{pH}$ of the mixed Ca-P solution, which was 6.8. At this $\mathrm{pH}$ value, hydroxyapatite is the more stable phase [29].

Electrospun samples containing different amounts of calcium and phosphate were fabricated by changing the initial concentration of the $\mathrm{Ca}$ and $\mathrm{P}$ starting solutions, while keeping constant all other parameters. Figure 3 reports SEM images of gelatin mats enriched with different amounts of $\mathrm{CaP}$ nanoparticles. All samples showed bead-free nanofibers with similar morphology and diameters in the range 100$300 \mathrm{~nm}$, indicating that the inclusion of $\mathrm{CaP}$ had no evident effect on the nanofiber diameter, as previously found by other authors using different types of inorganic phase $[16,17,19]$. Nanofibers from different samples had a smooth surface and no appreciable presence of nanoparticles at fibers surface, as also confirmed by the images at higher magnification of GCaP250 and GCaP375 in Figures 3(e) and 3(f), respectively. The presence of dispersed nanoparticles was appreciated by TEM analysis, especially for sample GCaP375, as it can be seen in Figures 4(b)-4(d): the inorganic phase was well distributed along the nanofibers in the form of nanoparticles with diameters of few tens of nanometers. On the other hand, in sample GCaP50 very few aggregates were visible and they were not homogeneously distributed along all the fibers (Figure 4(a)).

TGA analysis reported in Figure 5 shows that the weight residue at $700^{\circ} \mathrm{C}$, after the complete degradation of the polymeric organic phase, increased with the increasing of 


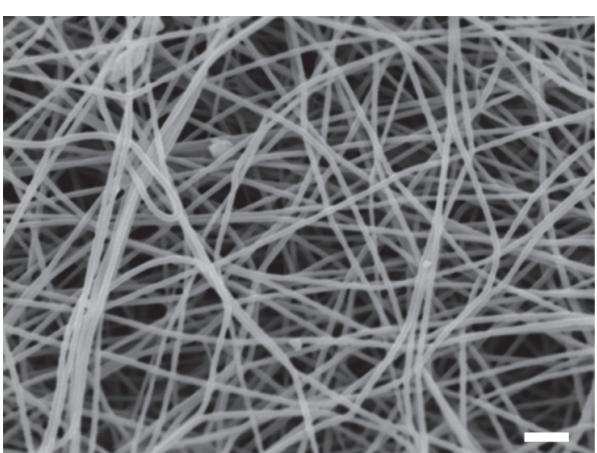

(a)

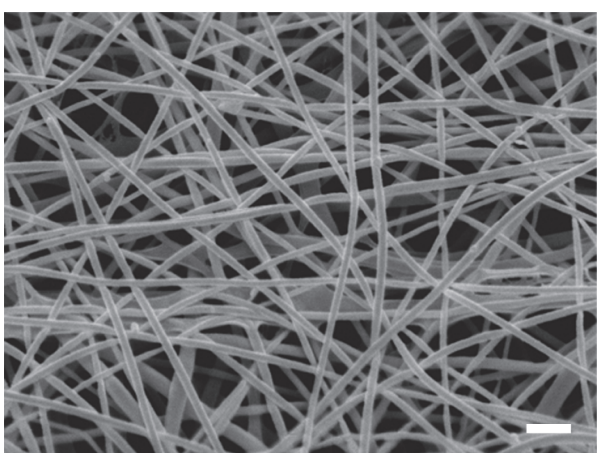

(c)

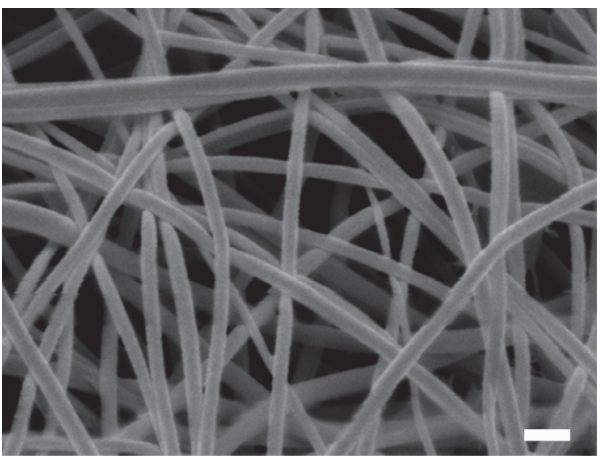

(e)

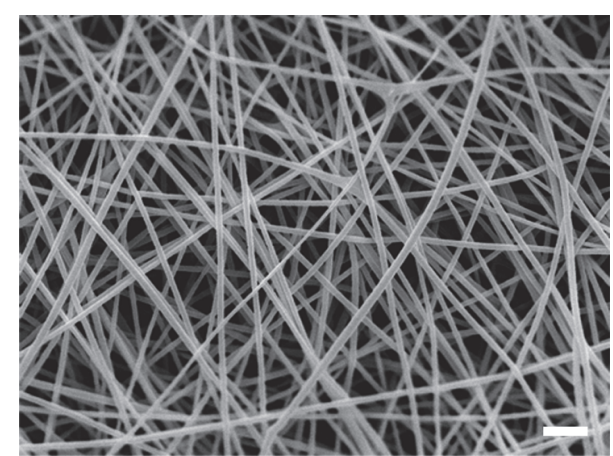

(b)

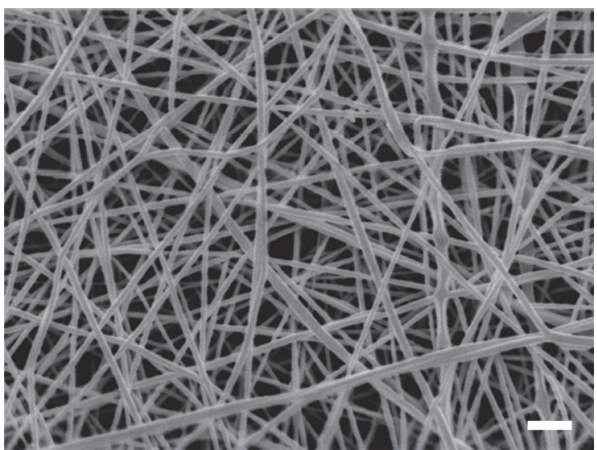

(d)

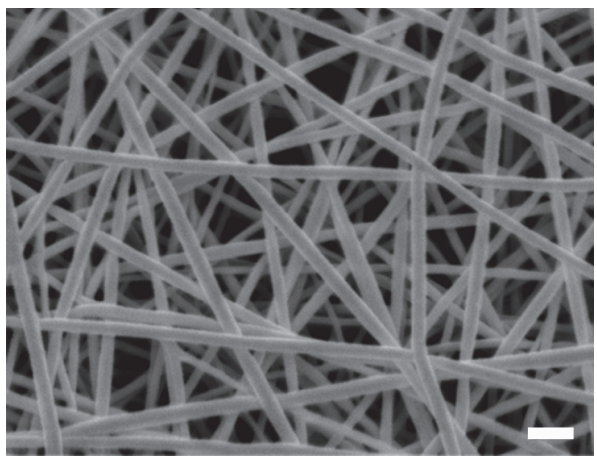

(f)

Figure 3: SEM micrographs of G (a), GCaP50 (b), GCaP250 ((c), (e)), and GCaP375 ((d), (f)). Scale bar: $2 \mu \mathrm{m}((\mathrm{a})-(\mathrm{d}))$; $1 \mu \mathrm{m}((\mathrm{e}),(\mathrm{f}))$.

the starting solutions concentration, demonstrating that the amount of inorganic phase inside the nanofibers can be modulated during the mat fabrication process. In particular, the residual weight percentage was $0 \%, 2,5 \%, 5 \%$, and $8 \%$ for G, GCaP50, GCaP250, and GCaP375, respectively. The results fit with the theoretical ones, calculated, taking into account all the ionic species present in the electrospinning solutions.

Figure 6 reports EDS spectra of GCaP50 and GCaP375 samples in the range $0-6 \mathrm{keV}$ (no peaks were observed at energies higher than $6 \mathrm{keV}$ ). As expected, $\mathrm{Ca}$ and $\mathrm{P}$ were detected together with $\mathrm{Cl}$ and $\mathrm{Na}$, which acted as counterions in the starting solutions. It is evident that peak intensities increase with the increasing of ionic concentrations in the starting solutions. It is pointed out that EDS analysis cannot distinguish the ions of the apatitic phase from those present in ionic form, if any: thus a quantitative measure of the apatitic phase is not reliable.
Tensile stress-strain analysis of the composite samples was carried out and compared with that of pure gelatin sample (mechanical data are reported in Table 1 and representative curves are reported in Figure 7). Mats display a typical elastoplastic behavior where the stress-to-strain ratio was constant for low strain values (corresponding to the elastic modulus) followed by a plastic deformation at higher strain up to failure. Mechanical properties were affected by the presence of the inorganic phase. In particular, with respect to the mats of pure gelatin, the addition of a small amount of $\mathrm{CaP}$ provoked a decrease of the value of the elastic modulus, $E$, of about $50 \%$ (compare G and GCaP50 samples). At higher $\mathrm{CaP}$ contents the value of the elastic modulus increased up to a value similar to that of pure gelatin in GCaP250 sample and an even greater value in GCaP375 sample. The stress at break values followed a similar trend while the strain at break followed an almost opposite trend. It is pointed 


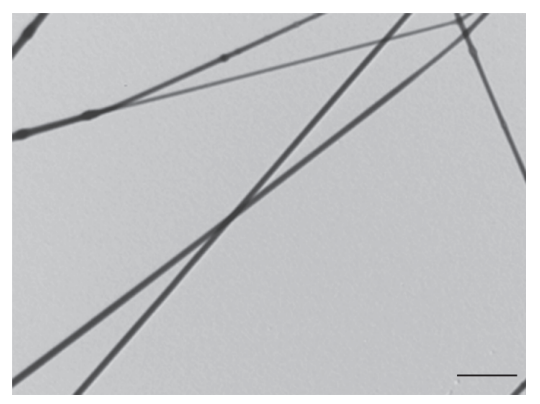

(a)

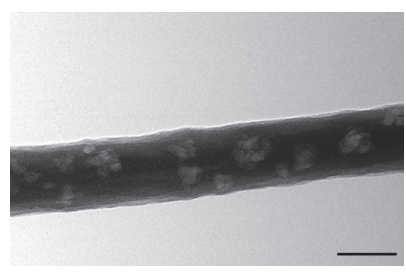

(c)

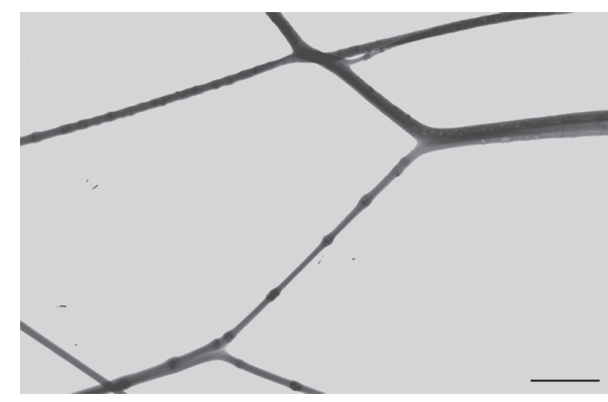

(b)

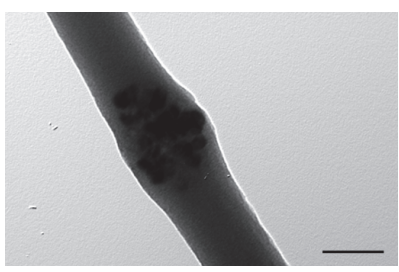

(d)

Figure 4: TEM images of GCaP50 (a) and of GCaP375 ((b)-(d)) samples. Scale bars: $1 \mu \mathrm{m}$ ((a), (b)); $100 \mathrm{~nm}((\mathrm{c}),(\mathrm{d}))$.

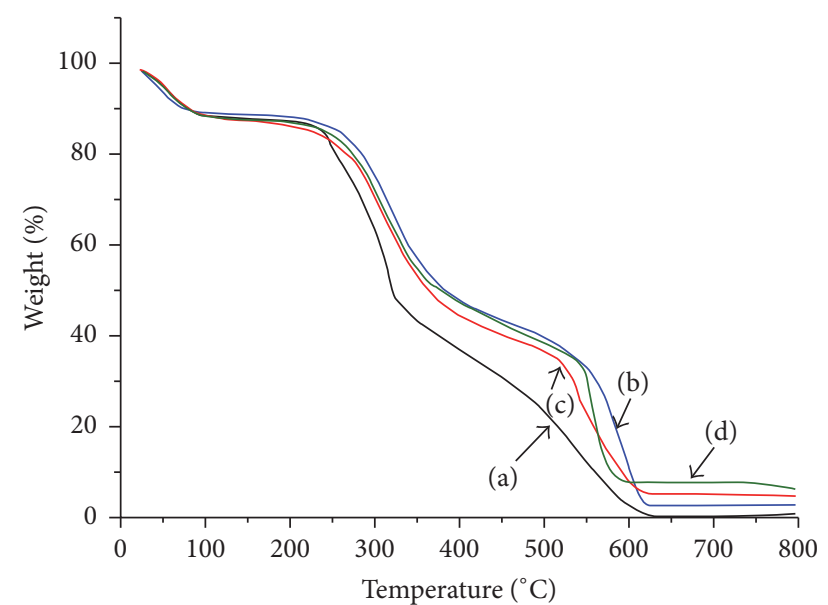

Figure 5: TGA curves of G (a), GCaP50 (b), GCaP250 (c), and GCaP375 (d).

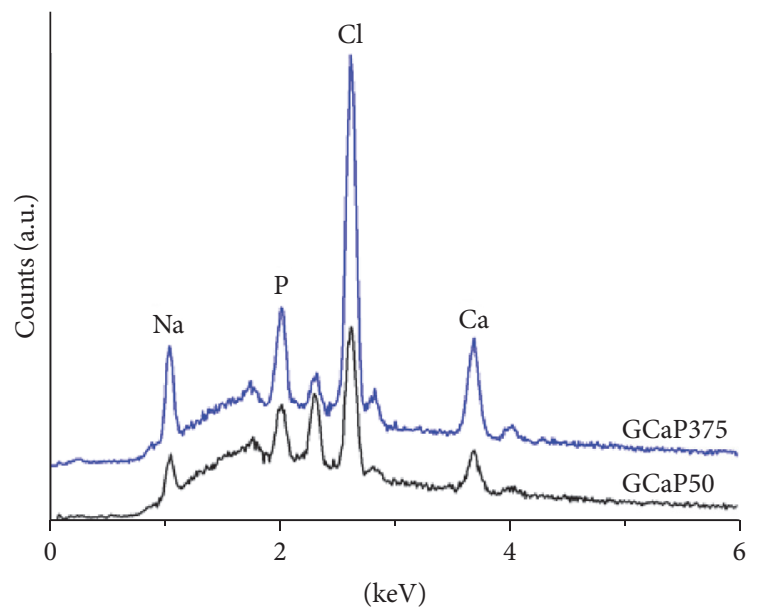

Figure 6: EDS spectra of GCaP50 and GCaP375.
TABle 1: Mechanical properties of G, GCaP50, GCaP250, and GCaP375: tensile modulus $(E)$, stress at break $\left(\sigma_{b}\right)$, and strain at break $\left(\varepsilon_{b}\right)$.

\begin{tabular}{lccc}
\hline Sample & $E(\mathrm{MPa})$ & $\sigma_{b}(\mathrm{MPa})$ & $\varepsilon_{b}(\%)$ \\
\hline G & $90 \pm 6$ & $3.5 \pm 0.4$ & $18 \pm 1$ \\
GCaP50 & $38 \pm 8$ & $2.8 \pm 0.3$ & $25 \pm 3$ \\
GCaP250 & $90 \pm 30$ & $4 \pm 1$ & $15 \pm 6$ \\
GCaP375 & $150 \pm 10$ & $5.4 \pm 0.5$ & $15 \pm 3$ \\
\hline
\end{tabular}

out that, in general, the addition of inorganic particles to a polymeric phase is known to enhance the mechanical strength and elastic modulus when the inorganic particles are fine and evenly dispersed. In the case of electrospun fibers, this is typically observed for very low amounts of filler, while at higher nanoparticles concentrations the mechanical properties get weaker as a consequence of nanoparticles agglomeration [17, 19, 30]. However, some authors found improvement of mat mechanical properties also at very high concentrations of inorganic additive (up to $40 \mathrm{wt} \%$ ) $[15,22]$. In our case, the worsening of the mechanical properties of the GCaP50 sample with respect to $G$ mat might be ascribed to the fact that, at low $\mathrm{CaP}$ concentrations, the inorganic phase is not homogeneously distributed along all polymer nanofibers and generates discontinuity zones acting as weak points (see Figure 4(a)). On the contrary, at higher nanoparticle loadings the well-distributed inorganic phase (see Figures $4(\mathrm{~b})-4(\mathrm{~d})$ ) can act as reinforcement.

\section{Conclusions}

In this work we electrospun gelatin nanofibers loaded with calcium phosphate nanoparticles by means of an innovative triaxial needle that was proved to be effective in electrospinning a polymer solution with the concomitant fast 


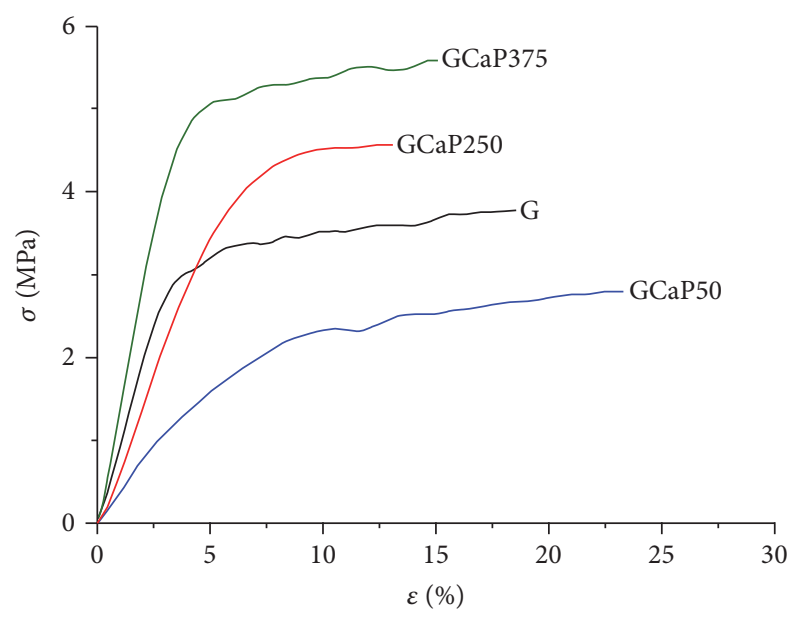

FIgUre 7: Stress-strain curves of G, GCaP50, GCaP250, and GCaP375.

coprecipitation of inorganic nanoparticles from calcium and phosphate aqueous solutions. XRD analysis confirmed that the nanoparticles generated inside the nanofibers were a poorly crystalline apatitic phase and TEM images showed that nanoparticles were homogenously dispersed in the gelatin nanofibers, thus overcoming some drawbacks of other commonly employed methods for fabricating nanocomposite electrospun scaffolds. Furthermore, by using the special triaxial needle we were able to modulate the amount of inorganic phase added inside the nanofibers that in turn conditioned the mechanical properties of mats. The innovative method proposed in this work, besides ensuring a homogenous dispersion of the inorganic phase within polymeric fibers, prospectively is suitable for fabricating electrospun scaffolds with graded composition, by simply controlling the flow rate of the different solutions involved in the process.

\section{Competing Interests}

The authors declare that they have no competing interests.

\section{Acknowledgments}

The authors acknowledge the Italian Ministry for Education, University and Research (MIUR) for financial support. Maria Letizia Focarete acknowledges the support of FP7 COST Action MP1206 "Electrospun Nano-Fibres for Bioinspired Composite Materials and Innovative Industrial Applications.”

\section{References}

[1] R. Sakina and M. Ali, "An appraisal of the efficacy and effectiveness of nanoscaffolds developed by different techniques for bone tissue engineering applications: electrospinning a paradigm shift," Advances in Polymer Technology, vol. 33, no. 4, Article ID 21429, 2014.

[2] R. Khajavi, M. Abbasipour, and A. Bahador, "Electrospun biodegradable nanofibers scaffolds for bone tissue engineering,"
Journal of Applied Polymer Science, vol. 133, no. 3, Article ID 42883, 2016.

[3] C. He, W. Nie, and W. Feng, "Engineering of biomimetic nanofibrous matrices for drug delivery and tissue engineering," Journal of Materials Chemistry B, vol. 2, no. 45, pp. 7828-7848, 2014.

[4] N. Reznikov, R. Shahar, and S. Weiner, "Bone hierarchical structure in three dimensions," Acta Biomaterialia, vol. 10, no. 9, pp. 3815-3826, 2014.

[5] M. Okamoto and B. John, "Synthetic biopolymer nanocomposites for tissue engineering scaffolds," Progress in Polymer Science, vol. 38, no. 10-11, pp. 1487-1503, 2013.

[6] J. Li, B. A. Baker, X. Mou et al., "Biopolymer/calcium phosphate scaffolds for bone tissue engineering," Advanced Healthcare Materials, vol. 3, no. 4, pp. 469-484, 2014.

[7] A. J. Wagoner Johnson and B. A. Herschler, "A review of the mechanical behavior of $\mathrm{CaP}$ and $\mathrm{CaP} /$ polymer composites for applications in bone replacement and repair," Acta Biomaterialia, vol. 7, no. 1, pp. 16-30, 2011.

[8] K. Rezwan, Q. Z. Chen, J. J. Blaker, and A. R. Boccaccini, "Biodegradable and bioactive porous polymer/inorganic composite scaffolds for bone tissue engineering," Biomaterials, vol. 27, no. 18, pp. 3413-3431, 2006.

[9] V. Guarino, A. Gloria, M. G. Raucci, R. De Santis, and L. Ambrosio, "Bio-inspired composite and cell instructive platforms for bone regeneration," International Materials Reviews, vol. 57, no. 5, pp. 256-275, 2012.

[10] C. Gualandi, A. Celli, A. Zucchelli, and M. L. Focarete, "Nanohybrid materials by electrospinning," in Organic-Inorganic Hybrid Nanomaterials, S. Kalia and Y. Haldorai, Eds., vol. 267 of Advances in Polymer Science, pp. 87-142, Springer, Cham, Switzerland, 2015.

[11] J. Xie, S. Zhong, B. Ma, F. D. Shuler, and C. T. Lim, “Controlled biomineralization of electrospun poly( $\varepsilon$-caprolactone) fibers to enhance their mechanical properties," Acta Biomaterialia, vol. 9, no. 3, pp. 5698-5707, 2013.

[12] Z. X. Meng, H. F. Li, Z. Z. Sun, W. Zheng, and Y. F. Zheng, "Fabrication of mineralized electrospun PLGA and PLGA/gelatin nanofibers and their potential in bone tissue engineering," Materials Science and Engineering: C, vol. 33, no. 2, pp. 699-706, 2013.

[13] M. O. Choi and Y.-J. Kim, "Fabrication of gelatin/calcium phosphate composite nanofibrous membranes by biomimetic mineralization," International Journal of Biological Macromolecules, vol. 50, no. 5, pp. 1188-1194, 2012.

[14] P. Torricelli, M. Gioffrè, A. Fiorani et al., "Co-electrospun gelatin-poly(L-lactic acid) scaffolds: modulation of mechanical properties and chondrocyte response as a function of composition," Materials Science and Engineering C, vol. 36, no. 1, pp. 130-138, 2014.

[15] N. T. Ba Linh, K.-H. Lee, and B.-T. Lee, "Functional nanofiber mat of polyvinyl alcohol/gelatin containing nanoparticles of biphasic calcium phosphate for bone regeneration in rat calvaria defects," Journal of Biomedical Materials Research-Part A, vol. 101, no. 8, pp. 2412-2423, 2013.

[16] F. Peng, X. Yu, and M. Wei, "In vitro cell performance on hydroxyapatite particles/poly(L-lactic acid) nanofibrous scaffolds with an excellent particle along nanofiber orientation," Acta Biomaterialia, vol. 7, no. 6, pp. 2585-2592, 2011.

[17] A. Bianco, E. Di Federico, and I. Cacciotti, "Electrospun poly( $\varepsilon$-caprolactone)-based composites using synthesized $\beta$ tricalcium phosphate," Polymers for Advanced Technologies, vol. 22, no. 12, pp. 1832-1841, 2011. 
[18] A. B. Kutikov and J. Song, "An amphiphilic degradable polymer/hydroxyapatite composite with enhanced handling characteristics promotes osteogenic gene expression in bone marrow stromal cells," Acta Biomaterialia, vol. 9, no. 9, pp. 8354-8364, 2013.

[19] H. Kim, L. Che, Y. Ha, and W. Ryu, "Mechanically-reinforced electrospun composite silk fibroin nanofibers containing hydroxyapatite nanoparticles," Materials Science and Engineering C, vol. 40, pp. 324-335, 2014.

[20] T. Chae, H. Yang, F. Ko, and T. Troczynski, "Bio-inspired dicalcium phosphate anhydrate/poly(lactic acid) nanocomposite fibrous scaffolds for hard tissue regeneration: in situ synthesis and electrospinning," Journal of Biomedical Materials Research-Part A, vol. 102, no. 2, pp. 514-522, 2014.

[21] H. Zhang, Q.-W. Fu, T.-W. Sun et al., "Amorphous calcium phosphate, hydroxyapatite and poly(d,l-lactic acid) composite nanofibers: electrospinning preparation, mineralization and in vivo bone defect repair," Colloids and Surfaces B: Biointerfaces, vol. 136, pp. 27-36, 2015.

[22] H.-W. Kim, J.-H. Song, and H.-E. Kim, "Nanofiber generation of gelatin-hydroxyapatite biomimetics for guided tissue regeneration," Advanced Functional Materials, vol. 15, no. 12, pp. 19881994, 2005.

[23] J.-H. Song, H.-E. Kim, and H.-W. Kim, "Electrospun fibrous web of collagen-apatite precipitated nanocomposite for bone regeneration," Journal of Materials Science: Materials in Medicine, vol. 19, no. 8, pp. 2925-2932, 2008.

[24] T. Kokubo, H. Kushitani, S. Sakka, T. Kitsugi, and T. Yamamuro, "Solutions able to reproduce in vivo surface-structure changes in bioactive glass-ceramic A-W3," Journal of Biomedical Materials Research, vol. 24, no. 6, pp. 721-734, 1990.

[25] F. Barrère, C. M. Van Der Valk, G. Meijer, R. A. J. Dalmeijer, K. De Groot, and P. Layrolle, "Osteointegration of biomimetic apatite coating applied onto dense and porous metal implants in femurs of goats," Journal of Biomedical Materials Research - Part B Applied Biomaterials, vol. 67, no. 1, pp. 655-665, 2003.

[26] F. Barrère, C. M. van der Valk, R. A. J. Dalmeijer et al., "Osteogenecity of octacalcium phosphate coatings applied on porous metal implants," Journal of Biomedical Materials Research Part A, vol. 66, no. 4, pp. 779-788, 2003.

[27] A. Bigi, E. Boanini, B. Bracci et al., "Nanocrystalline hydroxyapatite coatings on titanium: a new fast biomimetic method," Biomaterials, vol. 26, no. 19, pp. 4085-4089, 2005.

[28] B. Bracci, P. Torricelli, S. Panzavolta, E. Boanini, R. Giardino, and A. Bigi, "Effect of $\mathrm{Mg} 2+, \mathrm{Sr} 2+$, and $\mathrm{Mn} 2+$ on the chemicophysical and in vitro biological properties of calcium phosphate biomimetic coatings," Journal of Inorganic Biochemistry, vol. 103, no. 12, pp. 1666-1674, 2009.

[29] M. S.-A. Johnsson and G. H. Nancollas, "The role of Brushite and octacalcium phosphate in apatite formation," Critical Reviews in Oral Biology and Medicine, vol. 3, no. 1-2, pp. 61-82, 1992.

[30] S.-H. Jegal, J.-H. Park, J.-H. Kim et al., "Functional composite nanofibers of poly(lactide-co-caprolactone) containing gelatinapatite bone mimetic precipitate for bone regeneration," Acta Biomaterialia, vol. 7, no. 4, pp. 1609-1617, 2011. 

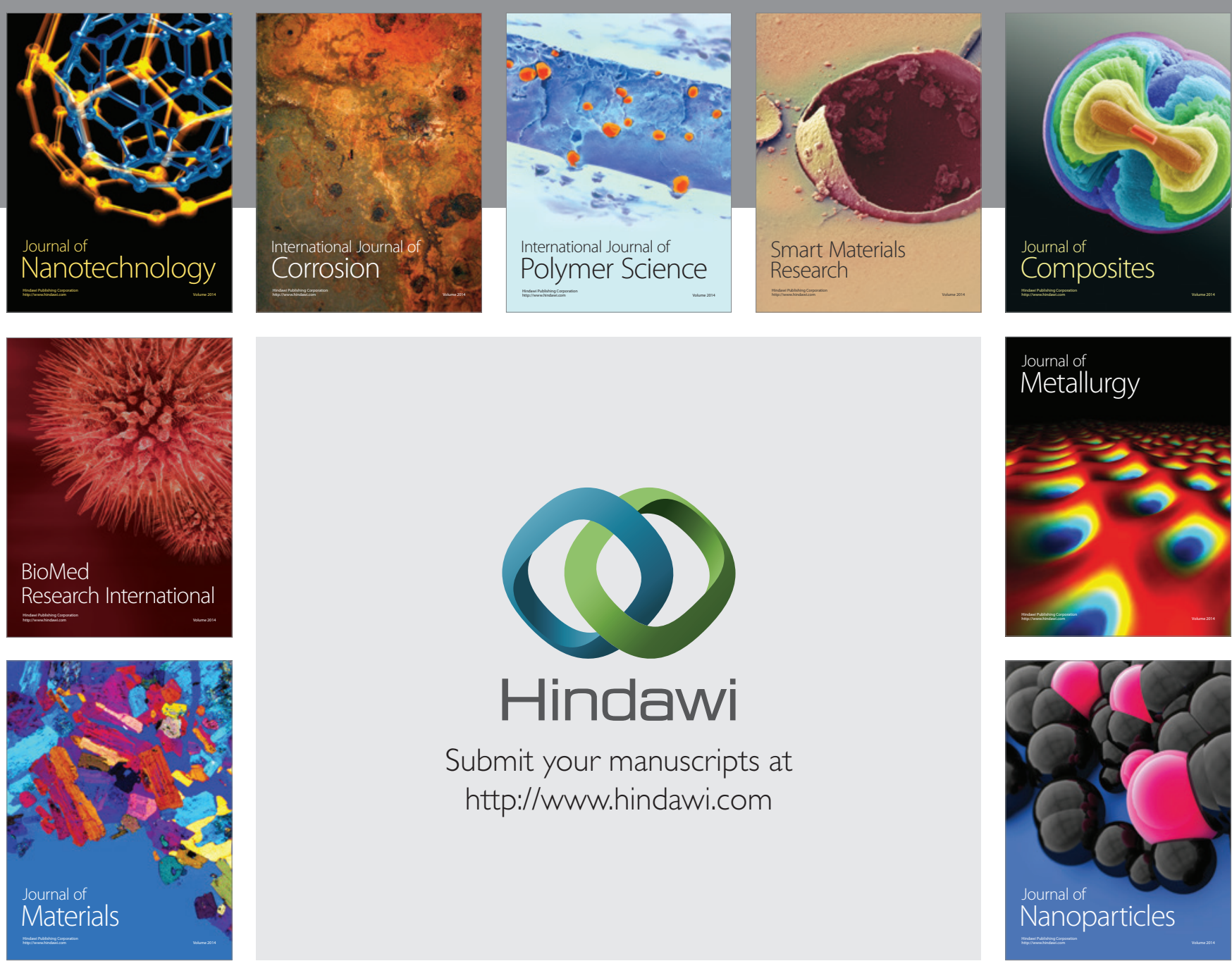

\section{Hindawi}

Submit your manuscripts at

http://www.hindawi.com

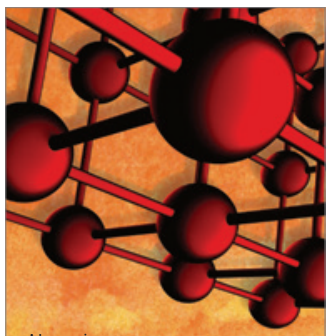

Materials Science and Engineering
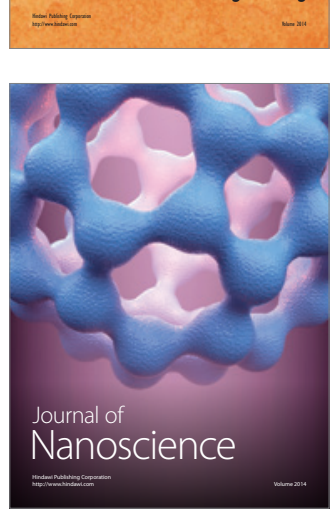
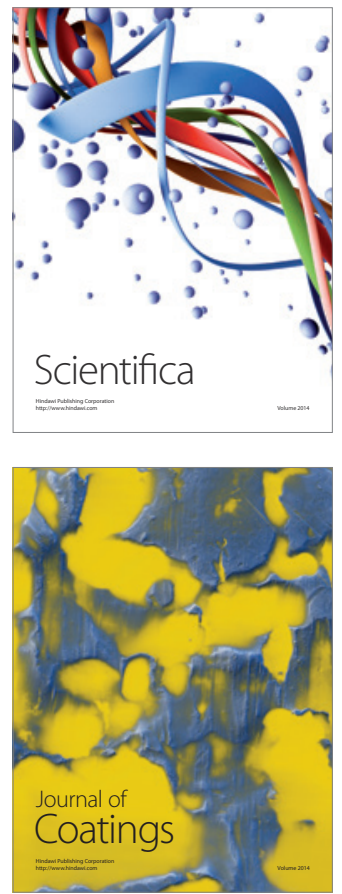
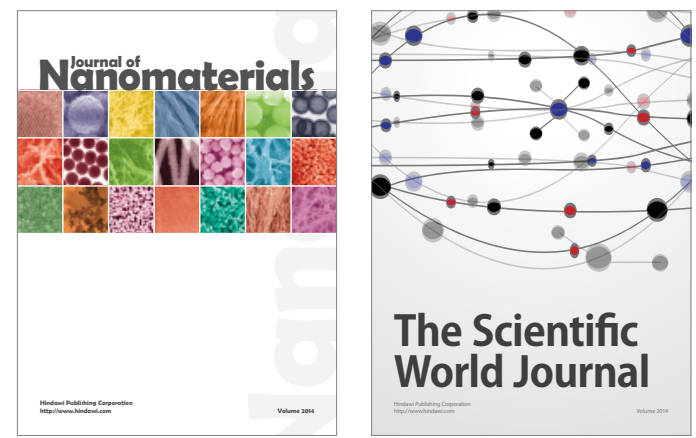

The Scientific World Journal
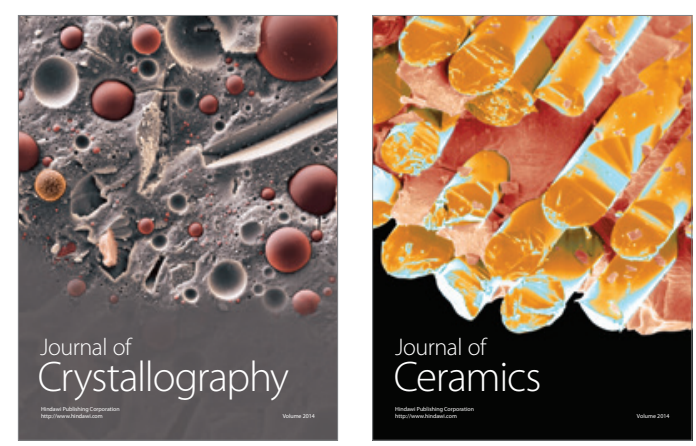
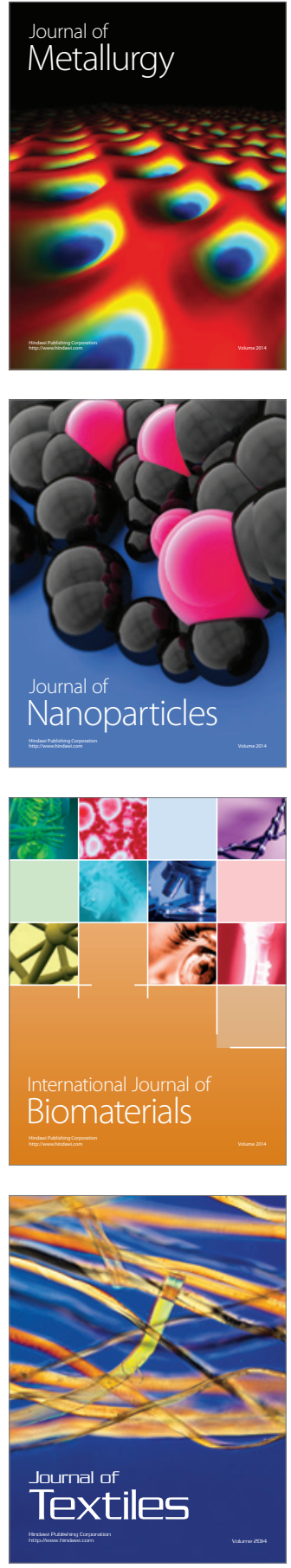